\title{
SPECTROSCOPIC PROPERTIES OF THE Ln-Ge COMPLEXES WITH DIETHYLENETRIAMINEPENTAACETIC ACID ${ }^{\S}$
}

\author{
Sergiy Smola ${ }^{\mathrm{a}}$, Natalya Rusakova ${ }^{\mathrm{a}}$, Elena Martsinko ${ }^{\mathrm{b}}$, Inna Seifullina ${ }^{\mathrm{b}}$, Yuriy Korovin ${ }^{\mathrm{a}^{*}}$ \\ ${ }^{a}$ A.V. Bogatsky Physico-Chemical Institute, National Academy of Sciences of Ukraine, 65080 Odessa, Ukraine \\ ${ }^{b}$ I.I. Mechnikov Odessa National University, 65026 Odessa, Ukraine \\ *Corresponding author: E-mail: lantachem@te.net.ua; fax +380482 652 012; tel: +38 0482652038
}

\begin{abstract}
Four new heteronuclear lanthanide complexes with general formula $[\mathrm{Ge}(\mathrm{OH})(\mu-\mathrm{HDTPA}) \operatorname{LnGe}(\mathrm{OH})$ $(\mu$-DTPA $)](\mathrm{Ln}=\mathrm{Sm}-\mathrm{Dy})$ were synthesized and subsequently characterized by different physico-chemical methods. The structures of new compounds have been proposed. In considered complexes the $4 \mathrm{f}$-luminescence of three-charged ions of samarium, europium, terbium and dysprosium is realized at UV-excitation. It is noteworthy that it is the first observation of $4 \mathrm{f}$-luminescence in water solutions of heteronuclear $f$-p-complexes. The comparison of luminescent characteristics of hetero- and homonuclear landthanide complexes is described and discussed as well.
\end{abstract}

Keywords: Heteronuclear complexes; Lanthanides; Germanium; DTPA; Luminescence.

\section{INTRODUCTION}

The increasing number of the heteronuclear complexes involves the great interest in coordination chemistry. These species cause interest because of their properties which allow to consider them as perspective objects of researches both fundamental and applied orientation. Polyaminopolycarboxylic acids are the one of the most suitable organic ligands by means of which it is possible to receive heteronuclear species. In particular, the donor properties of diethylenetriaminepentaacetic acid (DTPA) allow to obtain the complexes internal coordination sphere of which includes simultaneously two different metals and more. However, the heteronuclear lanthanide complexes are studied much less in comparison with mononuclear ones, whereas lanthanide complexes with DTPA and its derivatives have attracted attention as potential contrast agents $[1,2]$. The overwhelming number of works is devoted to $f-d$ - and $f-s$-complexes. At the same time the data of $f-p$-complexes are singular $[3,4]$. Therefore we reported the preliminary results to gain data on the spectroscopic properties of the lanthanide-germanium complexes with DTPA.

\section{RESULTS AND DISCUSSIONS}

Heterometallic complexes of samarium, europium, terbium and dysprosium with germanium have been synthesized by interaction of the complex acid $\left[\mathrm{Ge}(\mathrm{OH})\left(\mathrm{H}_{2} \mathrm{DTPA}\right)\right] \cdot \mathrm{H}_{2} \mathrm{O}$ and the respective lanthanide acetates in aqueous solutions. The structure of these compounds was determined from the elemental, thermogravimetric, X-ray diffraction analysis, IR-spectroscopy.

On the basis of the results of elemental analysis it has been assumed that the ratio lanthanide : germanium : DTPA in obtained product equals $1: 2: 2$. The XRD patterns were characterized by the interplanar distance personal set which differed from mononuclear germanium complex ones. No impurity phases were detected in them. Thus, on the basis of practically identical set of interplanar distances the conclusion that they were isostructural was made. According to thermogravimetric analysis dehydration starts at $60^{\circ} \mathrm{C}$ and ends at $210^{\circ} \mathrm{C}$. The wide interval of this process up to high temperature is explained probably special expedient of water molecules packing due to the formation intra- and intermolecular hydrogen bonds that was mentioned for lanthanide complexes. Heteronuclear lanthanide complexes contain three water molecules in outer coordination sphere. Pyrolysis proceeds in one single sharp weight loss at 210$260^{\circ} \mathrm{C}$ (decarboxylation), while the formation of the inorganic residue is completed at $520-540^{\circ} \mathrm{C}$.

The mode of ligand coordination in lanthanide-germanium complexes was determined from the IR spectroscopy data in comparison with IR spectrum of mononuclear germanium complex. The IR spectra of the heteronuclear complexes were characterized with the following bands: in vibration region $v \mathrm{CH}$ one $\left(2990 \mathrm{~cm}^{-1}\right)$, that proves coordination of all three nitrogen atoms of $\mathrm{H}_{5} \mathrm{DTPA}$ by metal ions; $\delta \mathrm{GeOH}\left(880 \mathrm{~cm}^{-1}\right), v \mathrm{Ge}-\mathrm{N}\left(640 \mathrm{~cm}^{-1}\right), v \mathrm{C}=\mathrm{O}\left(1715 \mathrm{~cm}^{-1}\right)$ coordinated group $\mathrm{COOH}, v_{\text {as }} \mathrm{C}-\mathrm{O}\left(1595 \mathrm{~cm}^{-1}\right), v_{\mathrm{s}} \mathrm{C}-\mathrm{O}\left(1400 \mathrm{~cm}^{-1}\right)$ groups COO-, bounded with $\mathrm{f}$-metal; $v_{\text {as }} \mathrm{C}-\mathrm{O}$ (shoulder is about $\left.1700 \mathrm{~cm}^{-1}\right)$ and $v_{\mathrm{s}} \mathrm{C}-\mathrm{O}\left(1330 \mathrm{~cm}^{-1}\right)$ carboxylate ions bounded with germanium; wide band $v \mathrm{OH}$ with maximum about $3400 \mathrm{~cm}^{-1}$. Thus, it can be concluded that saturation of germanium coordination number up to 6 occured at the expense of valence linkages with hydroxo- and three carboxylic groups, and also coordinate linkages to two nitrogen atoms of ligand. It was established that all DTPA donor centers are interlinked with metals in complexes. It corresponds to absence of inner sphere water molecules in these heteronuclear complexes.

\footnotetext{
$\S$ Material presented at the XV-th Conference "Physical Methods in Coordination and Supramolecular Chemistry", September 27 - October 1, 2006, Chişinău, Moldova
} 
All data analysis obtained with the help of different physico-chemical methods allow assuming that $p$-f-complexes are three nuclear ones. Coordinated polyhedron of germanium is the same as in complex acid $\left[\mathrm{Ge}(\mathrm{OH})\left(\mathrm{H}_{2} \mathrm{DTPA}\right)\right] \cdot \mathrm{H}_{2} \mathrm{O}$. On the basis of obtained data and taking into account the coordination figures, oxidation degrees characterized typically for investigated metals (as well as isostructural of synthesized complexes), their structure schemes can be proposed as it is given in Fig. 1. Coordination polyhedron of lanthanide is the "distorted octahedron" forming for account of tridentate coordination of two complex anions [Ge(OH)DTPA $]^{2-}$ and $[\mathrm{Ge}(\mathrm{OH}) \mathrm{HDTPA}]^{-}$with the closing of four glycine metal cycles.

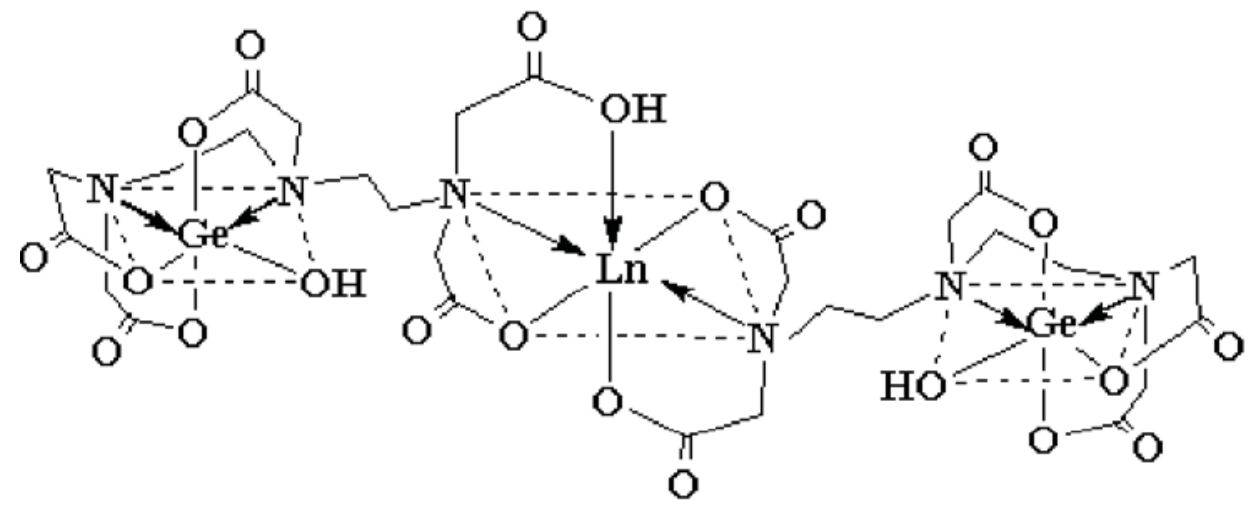

Fig 1. Structure of the lanthanide-germanium complexes $(\mathrm{Ln}=\mathrm{Sm}-\mathrm{Dy})$.

The UV-Vis absorption spectra of heteronuclear terbium- and europium-germanium complexes have been shown in Fig. 2. Absorption spectrum of Tb(Ge-DTPA) (Fig. 2a) were shifted hypsochromically as compared to Ge-DTPA spectrum and consisted of three bands (as well as for mononuclear complexes): intensive one at $195 \mathrm{~nm}$ and two less intensive bands within the range $255-260 \mathrm{~nm}$ and $350 \mathrm{~nm}$. Samarium- and dysprosium-germanium complexes show the similar features. In contrast to previous, a new band in Eu(Ge-DTPA) absorption spectrum appeared at 427 $\mathrm{nm}$ (Fig. 2b), that was not typically for Ge-DTPA. Other three bands noted in the ligand absorption spectrum shifted batochromically.
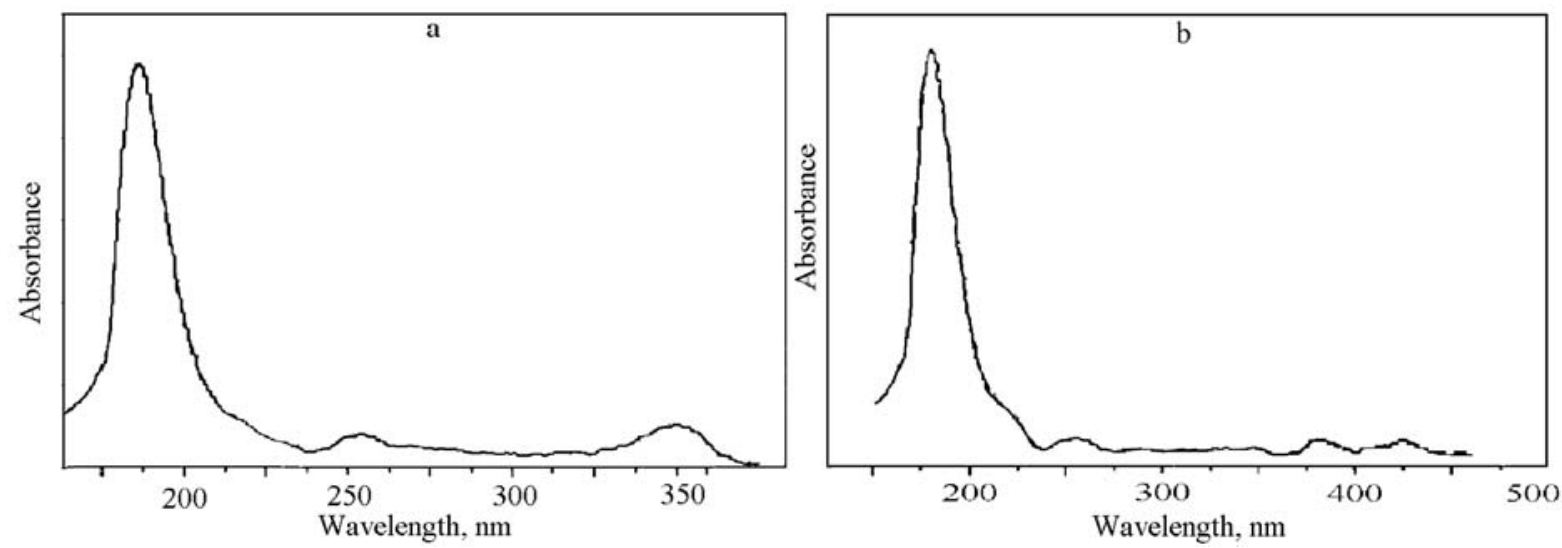

Fig 2. UV absorption spectra of $\mathrm{Tb}(\mathrm{Ge}-\mathrm{DTPA})_{2}$ (a) and $\mathrm{Eu}(\mathrm{Ge}-\mathrm{DTPA})_{2}$ (b) in $\mathrm{H}_{2} \mathrm{O}$.

The luminescent excitation spectra (Fig.3) of lanthanide complexes were measured at 298 K. The luminescence excitation spectrum of $\mathrm{Tb}(\mathrm{Ge}-\mathrm{DTPA})_{2}$ complex under the emission of $545 \mathrm{~nm}$ is shown in Fig 3a. In narrow-wavelength region there was one excitation peak with maximum at $235 \mathrm{~nm}$. In long-wavelength region two strong excitation peaks were observed at 358 and $379 \mathrm{~nm}$, which practically coincides with spectra of excitation of mononuclear complexes. Selected excitation under these wavelengths, the emission spectra show the similar luminescent position except for different luminescent intensities. The analogous picture is observed in excitation luminescence spectra of samarium and dysprosium heteronuclear complexes. Luminescence excitation spectrum of Eu(Ge-DTPA), under the red emission of $617 \mathrm{~nm}$ is illustrated in Fig 3b. Unlike a mononuclear complex of europium which is characterized by two peaks with maxima at $310 \mathrm{~nm}$ and $400 \mathrm{~nm}$, the excitation spectrum of Eu(Ge-DTPA) $)_{2}$ consisted of three peaks in long-wavelength region at 310, 400 and $431 \mathrm{~nm}$, situated separately.

The luminescent emission spectra of heteronuclear lanthanide complexes at room temperature are presented in Fig. 4 and 5. The increase of luminescence intensity for heteronuclear complexes in comparison with mononuclear complexes was observed (Tab. 1). Noteworthy, that the luminescence intensity of heteronuclear samarium, terbium or 
dysprosium complexes at various lengths of excitation waves was higher (up to 1.8, 2.1 and 2.5 times, respectively), than in the mono-complexes. At the same time, the luminescence of heteronuclear europium complex was higher (up to 1.7 times) as compared to Eu-DTPA complex only in the excitation region of 310-330 nm.
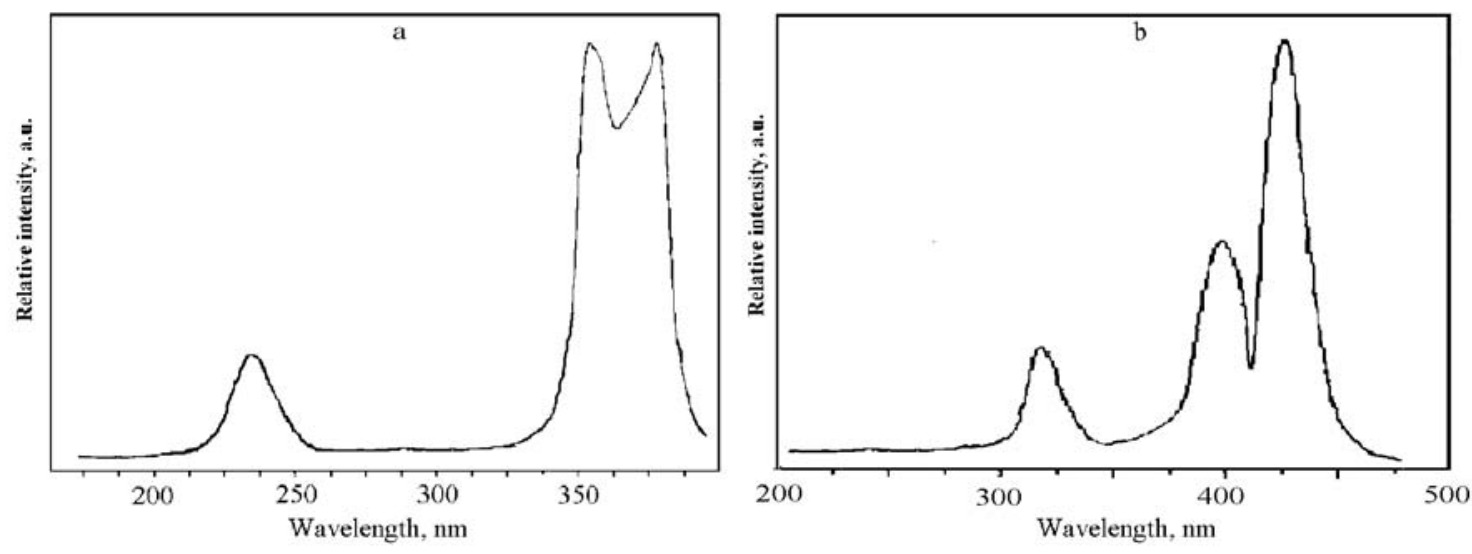

Fig. 3. Luminescence excitation spectra of Tb(Ge-DTPA $)_{2}$ (a) $\left(\lambda_{\text {em }}=545 \mathrm{~nm}\right)$ and $\mathrm{Eu}(\mathrm{Ge}-\mathrm{DTPA})_{2}$ (b) $\left(\lambda_{\mathrm{em}}=612 \mathrm{~nm}\right)$ in $\mathrm{H}_{2} \mathrm{O}$.

The luminescence spectra of the terbium-germanium complex (Fig. 4a) registered under long (358 nm) wavelength show the similar emission of $\mathrm{Tb}^{3+}$ ion. Four main peaks were characterized emission originated from the ${ }^{5} \mathrm{D}_{4} \rightarrow{ }^{7} \mathrm{~F}_{\mathrm{j}}$ $(\mathrm{j}=6,5,4,3)$ transition of $\mathrm{Tb}^{3+}$ ion. The strongest peak $\left(\lambda_{\max }=547 \mathrm{~nm} ;{ }^{5} \mathrm{D}_{4} \rightarrow{ }^{7} \mathrm{~F}_{5}\right.$ - transition $)$ is corresponded to nonhypersensitive transition. Luminescence quantum yield increases in 2.1 times as compared to homonuclear complex (Tab. 1) Luminescence lifetime decreases - $570 \mu \mathrm{sec}$ for Tb(Ge-DTPA) and $750 \mu \mathrm{sec}$ for Tb-DTPA complex.
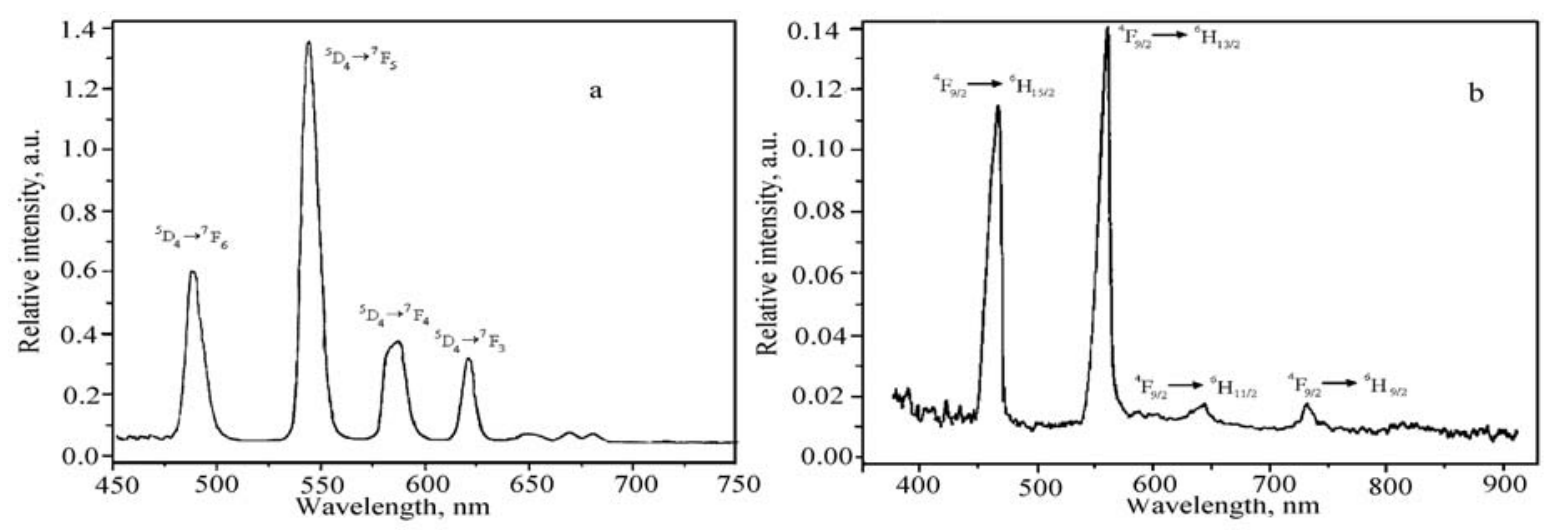

Fig. 4. Emission spectra of $\mathrm{Tb}(\mathrm{Ge}-\mathrm{DTPA})_{2}$ (a) $\left(\lambda_{\text {exc }}=358 \mathrm{~nm}\right)$ and Dy(Ge-DTPA $)_{2}(\mathrm{~b})\left(\lambda_{\mathrm{exc}}=338\right)$ complexes $\left(\mathrm{H}_{2} \mathrm{O}, 295 \mathrm{~K}\right)$.

The luminescence spectrum of $\mathrm{Dy}(\mathrm{Ge}-\mathrm{DTPA})_{2}$ (Fig 4b) show four apparent emission peaks $\left({ }^{4} \mathrm{~F}_{9 / 2} \rightarrow{ }^{6} \mathrm{H}_{\mathrm{J}} ; \mathrm{J}=15 / 2\right.$, $13 / 2,11 / 2,9 / 2)$ under the excitation $338 \mathrm{~nm}$. The highest emission was the ${ }^{4} \mathrm{~F}_{9 / 2} \rightarrow{ }^{6} \mathrm{H}_{13 / 2}$ hypersensitive transition. As it is shown in Tab. 1, terbium- and dysprosium-germanium complexes are characterized by the more strong emission than other heteronuclear lanthanide complexes for the more suitable energy match and more effective ligand-to-lanthanide ion energy transfer than $\mathrm{Eu}^{3+}$ and $\mathrm{Sm}^{3+}$, which is confirmed by values of quantum yields and luminescence lifetimes for these complexes. So, the characteristic transition of terbium ion is not such sensitive as europium ion to the nearby environment. The increasing of luminescence quantum yield of heteronuclear complex up to 2.5 times in comparison with homonuclear dysprosium complex was observed (Tab. 1).

The low luminescence emission spectrum of samarium heteronuclear complex was measured (Fig. 5a), which under excitation wavelength $360 \mathrm{~nm}$ exhibits four predominantly characteristic emission corresponded to the ${ }^{4} \mathrm{G}_{5 / 2} \rightarrow{ }^{6} \mathrm{H}_{\mathrm{J}}(\mathrm{J}=$ $5 / 2,7 / 2,9 / 2,11 / 2$ ) transitions of $\mathrm{Sm}^{3+}$ ion. The $601 \mathrm{~nm}$ peak (non-hypersensitive transition ${ }^{4} \mathrm{G}_{5 / 2} \rightarrow{ }^{6} \mathrm{H}_{7 / 2}$ ) is the strongest. As it is shown in Tab. 1, almost twofold increasing of quantum yield in comparison with homonuclear dysprosium complex was observed.

The luminescence spectrum of europium complex under the excitation of $310 \mathrm{~nm}$ shows three emission peaks, 
which correspond to the characteristic emission ${ }^{5} \mathrm{D}_{0} \rightarrow{ }^{7} \mathrm{~F}_{\mathrm{J}}(\mathrm{J}=1,2,4)$ transitions of $\mathrm{Eu}^{3+}$ ion, respectively. The $612 \mathrm{~nm}$ peak corresponding to hypersensitive transition $\left({ }^{5} \mathrm{D}_{0} \rightarrow{ }^{7} \mathrm{~F}_{2}\right)$ is the strongest and the band intensity ratio equals 1:2:1. Marginal changes of quantum yields were observed (Tab. 1), while luminescence lifetime increases in heneronuclear complex: $390 \mu \mathrm{sec}$ for Eu-DTPA and $450 \mu \mathrm{sec}$ for Eu(Ge-DTPA) ${ }_{2}$.
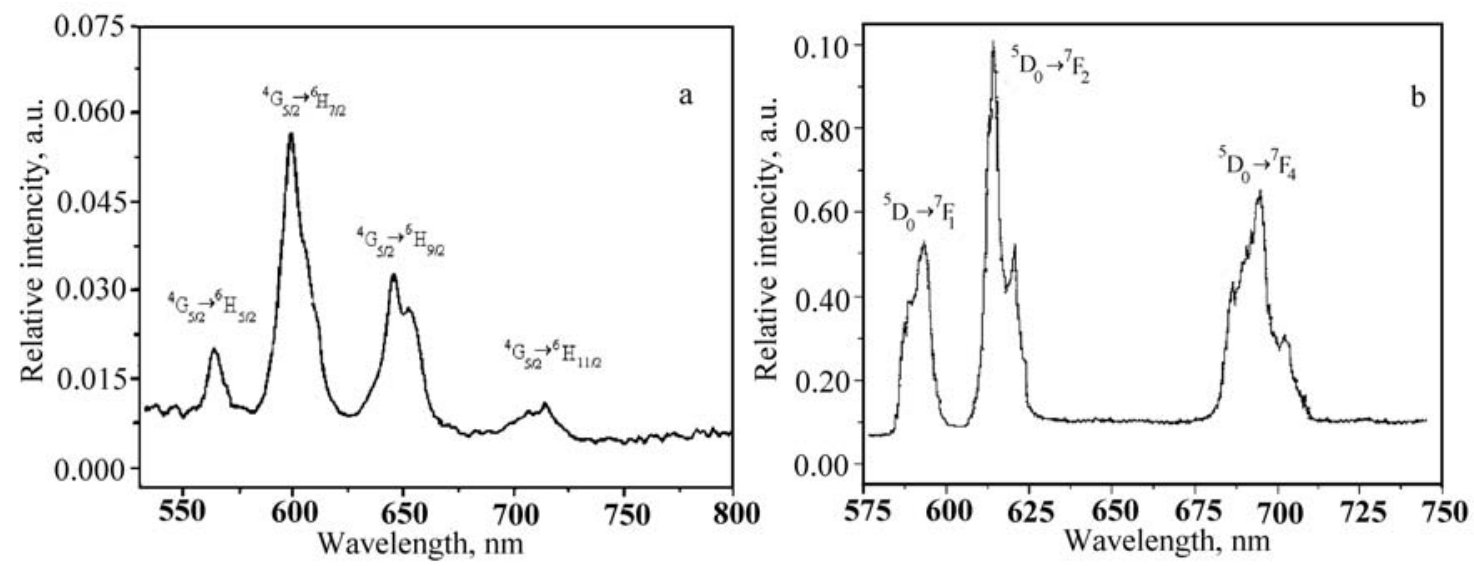

Fig. 5. Emission spectra of $\operatorname{Sm}(\mathrm{Ge}-\mathrm{DTPA})_{2}$ (a) $\left(\lambda_{\text {exc }}=360 \mathrm{~nm}\right)$ and $\mathrm{Eu}(\mathrm{Ge}-\mathrm{DTPA})_{2}(\mathrm{~b})\left(\lambda_{\mathrm{exc}}=310 \mathrm{~nm}\right)$ complexes $\left(\mathrm{H}_{2} \mathrm{O}, 295 \mathrm{~K}\right)$.

Table 1

Luminescent properties of $\operatorname{Ln}(\mathrm{Ge}-\mathrm{DTPA})_{2}$ complexes

\begin{tabular}{|c|c|c|c|}
\hline Complex & Luminescence quantum yield $\varphi^{\mathrm{a}}$ & $\varphi_{\mathrm{h}} / \varphi_{\mathrm{m}}{ }^{\mathrm{b}}$ & Lifetimes $\tau, \mu$ sec \\
\hline $\mathrm{Sm}(\mathrm{Ge}-\mathrm{DTPA})_{2}$ & 0.0086 & 1.8 & 73 \\
\hline $\mathrm{Eu}(\mathrm{Ge}-\mathrm{DTPA})_{2}$ & 0.015 & 1.7 & 450 \\
\hline $\mathrm{Tb}(\mathrm{Ge}-\mathrm{DTPA})_{2}$ & 0.517 & 2.1 & 570 \\
\hline $\mathrm{Dy}(\mathrm{Ge}-\mathrm{DTPA})_{2}$ & 0.026 & 2.5 & 220 \\
\hline
\end{tabular}

${ }^{\mathrm{a}}$ Errors are $\pm 10 \%$.

${ }^{\mathrm{b}} \varphi_{\mathrm{h}}$ and $\varphi_{\mathrm{m}}$ - Luminescence quantum yield of heteronuclear and mononuclear complexes, respectively.

\section{EXPERIMENTAL}

General. Elemental analysis (C, H, N) was carried out by an Perkin-Elmer CHN-240 analyzer. All X-ray diffraction (XRD) measurements were made with DRON-2.0 powder diffractometer ( $\mathrm{CuK}_{\alpha}$ radiation). The thermogravimetric analysis was performed on a Paulik-Paulik-Erday Q-1500D derivatograph, under air atmospere, over the temperature range $20-500^{\circ} \mathrm{C}$ at $5^{\circ} \mathrm{C} / \mathrm{min}$ speed of tests heating. The IR spectra were measured on a IR-75 spectrometer $(\mathrm{KBr}$ pellets). The UV-Vis absorption spectra were recorded with an Perkin-Elmer Lambda 9 spectrophotometer. The solvent (water) was used as a reference.

\section{Synthesis}

$\mathrm{Ln}\left(\mathrm{CH}_{3} \mathrm{COO}\right)_{3}(\mathrm{Ln}=\mathrm{Sm}-\mathrm{Dy})$ and DTPA were purchased from Aldrich (Gillingham, Dorset) and used as received. Distilled and deionized water $\left(18 \mathrm{M} \Omega \mathrm{cm}^{-1}\right)$ was used throughout. The preparation of Ln complexes with DTPA was described previously [5]. The ligand [ $\left.\mathrm{Ge}(\mathrm{OH})\left(\mathrm{H}_{2} \mathrm{DTPA}\right)\right] \cdot \mathrm{H}_{2} \mathrm{O}$ was synthesized according to [6].

$[\mathrm{Ge}(\mathrm{OH})(\mu$-HDTPA $) \mathrm{SmGe}(\mathrm{OH})(\mu-\mathrm{DTPA})] \cdot 3 \mathrm{H}_{2} \mathrm{O} \cdot \mathrm{Sm}\left(\mathrm{CH}_{3} \mathrm{COO}\right)_{3}(0.33 \mathrm{~g}, 0.001 \mathrm{~mol})$ and $\left[\mathrm{Ge}(\mathrm{OH})\left(\mathrm{H}_{2} \mathrm{DTPA}\right)\right] \cdot \mathrm{H}_{2} \mathrm{O}$ $(0.96 \mathrm{~g}, 0.002 \mathrm{~mol})$ were dissolved in $40 \mathrm{ml}$ of water. The solution was heated $\left(\sim 50^{\circ} \mathrm{C}\right)$ with permanent stiring for $30 \mathrm{~min}$. In two days the white precipitate was formed. The reaction product was separated on the filter, washed out by ethanol and ether and dried above anhydrous $\mathrm{CaCl}_{2}$ up to a constant mass. Yield $\sim 45 \%$. Anal. Found, \%: $\mathrm{C}, 30.29 ; \mathrm{H}, 4.10 ; \mathrm{N}$, 7.64; Ge, 13.70; Sm, 13.59; Calcd. for $\mathrm{C}_{28} \mathrm{H}_{39} \mathrm{~N}_{6} \mathrm{O}_{22} \mathrm{Ge}_{2} \mathrm{Sm}, \% \mathrm{C}, 30.36 ; \mathrm{H}, 3.52 ; \mathrm{N}, 7.54 ; \mathrm{Ge}, 13.03 ; \mathrm{Sm}, 13.50$.

$[\mathrm{Ge}(\mathrm{OH})(\mu-\mathrm{HDTPA}) \mathrm{EuGe}(\mathrm{OH})(\mu-\mathrm{DTPA})] \cdot 3 \mathrm{H}_{2} \mathrm{O}$ was synthesized following the similar procedure by the interaction of $\mathrm{Eu}\left(\mathrm{CH}_{3} \mathrm{COO}\right)_{3}(0.33 \mathrm{~g}, 0.001 \mathrm{~mol})$ and $\left[\mathrm{Ge}(\mathrm{OH})\left(\mathrm{H}_{2} \mathrm{DTPA}\right)\right] \cdot \mathrm{H}_{2} \mathrm{O}(0.96 \mathrm{~g}, 0.002 \mathrm{~mol})$. Yield $\sim 48 \%$. Anal. Found, \%: C, 30.37; H, 4.02; N, 7.93; Ge, 13.37; Eu, 13.70; Calcd for $\mathrm{C}_{28} \mathrm{H}_{39} \mathrm{~N}_{6} \mathrm{O}_{22} \mathrm{Ge}_{2} \mathrm{Eu}, \% \mathrm{C}, 30.32 ; \mathrm{H}, 3.52$; $\mathrm{N}, 7.53 ; \mathrm{Ge}, 13.02 ; \mathrm{Eu}, 13.63$.

$\left[\mathrm{Ge}(\mathrm{OH})(\mu\right.$-HDTPA $) \mathrm{TbGe}(\mathrm{OH})(\mu-\mathrm{DTPA}) \cdot 3 \mathrm{H}_{2} \mathrm{O}$ was synthesized following the similar procedure using $\mathrm{Tb}\left(\mathrm{CH}_{3} \mathrm{COO}\right)_{3}$ as a lanthanide salt $(0.001 \mathrm{~mol})$. Yield $\sim 46 \%$. Anal. Found, \%: C, 30.59; H, 3.96; N, 7.80; Ge, 12.65; $\mathrm{Tb}, 14.65$; Calcd for $\mathrm{C}_{28} \mathrm{H}_{39} \mathrm{~N}_{6} \mathrm{O}_{22} \mathrm{Ge}_{2} \mathrm{~Tb}, \% \mathrm{C}, 30.13 ; \mathrm{H}, 3.50 ; \mathrm{N}, 7.49 ; \mathrm{Ge}, 12.94 ; \mathrm{Tb}, 14.17$. 
$[\mathrm{Ge}(\mathrm{OH})(\mu-\mathrm{HDTPA}) \mathrm{DyGe}(\mathrm{OH})(\mu-\mathrm{DTPA})] \cdot 3 \mathrm{H}_{2} \mathrm{O}$ was synthesized following the similar procedure using $\mathrm{Dy}\left(\mathrm{CH}_{3} \mathrm{COO}\right)_{3}$ as a lanthanide salt $(0.001 \mathrm{~mol})$. Yield $\sim 36 \%$. Anal. Found, \%: C, 30.02; H, 3.92; N, 7.79; Ge, 12.28; Dy, 14.90; Calcd for $\mathrm{C}_{28} \mathrm{H}_{39} \mathrm{~N}_{6} \mathrm{O}_{22} \mathrm{Ge}_{2} \mathrm{Dy}, \%$ C, 29.85; H, 3.46; N, 7.46; Ge, 12.90; Dy, 14.44 .

The synthesized heteronuclear complexes of the composition $[\mathrm{Ge}(\mathrm{OH})(\mu-\mathrm{HDTPA}) \mathrm{LnGe}(\mathrm{OH})(\mu-\mathrm{DTPA})]$ are stable in air, soluble in water and insoluble in majority of the widespread used organic solvents.

Luminescence measurements. Excitation and luminescence spectra were recorded using an SDL-2 spectrometer designed for the study of excitation spectra and luminescence radiation over the range 200-800 nm for liquid and solid samples. The excitation source was a xenon lamp Xe-150. The spectrometer was also equipped with monochromators MDR-12 and MDR-23. The radiation of the sample was recorded at an angle of $90^{\circ} \mathrm{C}$ to the exciting radiation. The luminescence lifetime $(\tau)$ data were obtained by means of a SDL-1 spectrofluorimeter (LOMO Association, St. Petersburg, Russia) with a LGI-21 nitrogen laser, with pulse duration of 8-10 ns at a wavelength of $337 \mathrm{~nm}$ and analyzed by iterative reconvolution and non-linear least-squares method [7]. The luminescence quantum yields $(\varphi)$ were obtained by the method described by Haas and Stein [8] with the standards $\left[\mathrm{Ru}(\text { bipy })_{3}\right]^{2-}\left(\varphi=0.028\right.$ in aerated water) for the $\mathrm{Sm}^{3+}$ and $\mathrm{Eu}^{3+}$ complexes and quinine sulphate $\left(\varphi=0.546\right.$ in $\left.\mathrm{H}_{2} \mathrm{SO}_{4} 1 \mathrm{~N}\right)$ for the $\mathrm{Tb}^{3+}$ and $\mathrm{Dy}^{3+}$ complexes. The measured values were corrected for the refractive indices. The triplet level position was obtained from phosphorescence spectra of gadolinium-germanium complex with DTPA at $77 \mathrm{~K}$.

\section{CONCLUSIONS}

The interaction of $\left[\mathrm{Ge}(\mathrm{OH})\left(\mathrm{H}_{2} \mathrm{DTPA}\right)\right] \cdot \mathrm{H}_{2} \mathrm{O}$ ligand with lanthanide salts leads to the formation of the new heteronuclear compounds with general formula $[\mathrm{Ge}(\mathrm{OH})(\mu-\mathrm{HDTPA}) \mathrm{LnGe}(\mathrm{OH})(\mu-\mathrm{DTPA})](\mathrm{Ln}=\mathrm{Sm}-\mathrm{Dy})$. According to structure proposed lanthanide ions coordinate two complex anions $[\mathrm{Ge}(\mathrm{OH}) \mathrm{DTPA}]^{2-}$ and $[\mathrm{Ge}(\mathrm{OH}) \mathrm{HDTPA}]^{-}$with the closing of four glycine metal cycles. The coordination polyhedron of lanthanide is the "distorted octahedron" while the germanium coordinated polyhedron was not changed. The spectroscopic properties of these complexes have been studied. The energy match between the ligand and lanthanide ions has been examined to predict that the energy transfer process exists between the ligand and $\mathrm{Ln}^{3+}$. Terbium complex has the most efficient energy transfer. The increasing of luminescence intensity, quantum yields as compared to homonuclear lanthanide complexes with DTPA was observed. Since germanium is not the sensitizer of $4 \mathrm{f}$-luminescence then it plays a role of original organizer for the structure of heteronuclear complexes.

\section{REFERENCES}

[1] Bianchi A., Calabi L., Corana F., Fontana S., Losi P., Maiocchi A., Paleari L., Valtancoli B. Coord. Chem. Rev. 2000, 204, 309-393.

[2] Langereis S., Kooistra H.-A. T., van Genderen M. H. P., Meijer E. W. Org. Biomol. Chem. 2004, 2, $1271-1274$.

[3] Wullens H., Bodart N., Devillers M. J. Solid State Chem. 2002, 167, 494-507.

[4] Stavila V., Gulea A., Popa N., Shova S., Merbach A., Simonov Yu., Lipkowski J. Inorg. Chem. Commun. 2004, 7, 634-637.

[5] Moeller T., Thompson L. C. J. Inorg. Nucl. Chem. 1962, 24, 499 - 510.

[6] Seifullina I., Martsinko E., Iliukhin A., Sergienko V. Russian J. Inorg. Chem. 1998, 43, 1509 - 1513.

[7] O’Connor D. V., Ware W.R., Andre J.C. J. Phys. Chem. 1979, 83, 1333-1343.

[8] Haas Y., Stein G. J. Phys. Chem. 1971, 75, 3668-3681. 